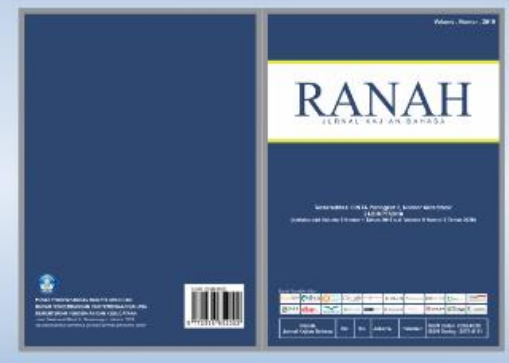

Ranah: Jurnal Kajian Bahasa

ojs.badanbahasa.kemdikbud.go.id/jurnal/index.php/jurnal_ranah

p-ISSN: $2338-8528$

e-ISSN: $2579-8111$

\title{
INOVASI DAN RETENSI FONOLOGIS PROTO BAHASA MELAYU PADA BAHASA MELAYU RIAU DIALEK PESISIR
}

(Phonological Innovations and Retentions of Malay Proto-language

within Riau Malay Coastal Dialect)

\author{
Ubaidillah $^{\text {a }}$ dan Norlailib \\ ${ }^{\mathrm{a}, \mathrm{b}}$ UIN Sunan Kalijaga Yogyakarta \\ ubaidillah@uin-suka.ac.id
}

Naskah Diterima Tanggal 15 April 2019-Direvisi Akhir Tanggal 21 April 2020-Disetujui Tanggal 22 Mei 2020 doi: https://doi.org/10.26499/rnh/v9i1.1392

\begin{abstract}
Abstrak
Bahasa Melayu merupakan salah satu bahasa dunia yang memiliki banyak pengguna. Salah satu daerah pengguna bahasa Melayu adalah Riau. Bahasa Melayu Riau memiliki sedikit perbedaan-perbedaan dalam leksikonnya sehingga bisa dikatakan sebagai subdialek. Oleh karena itu, perlu dilakukan penelitian lebih jauh mengenai bahasa komunikasi Melayu Riau, tepatnya bahasa Melayu Riau dialek Pesisir yang digunakan di Kecamatan Tembilahan dengan menggunakan kajian diakronis. Penelitian ini bertujuan untuk mengetahui gambaran refleks fonem-fonem protobahasa Melayu pada bahasa Melayu Riau dialek Pesisir di Kecamatan Tembilahan yang kemudian dilanjutkan dengan membuat kaidah-kaidah perubahan fonem-fonem protobahasa Melayu pada bahasa Melayu Riau dialek Pesisir di Kecamatan Tembilahan berikut kaidah retensi fonem-fonemnya. Metode yang digunakan dalam penelitian ini adalah metode deduktif kualitatif yang menerapkan teknik rekonstruksi dari atas ke bawah (top-down reconstruction). Hasil yang diperoleh dalam penelitian ini adalah terdapat kaidah inovasi-inovasi Melayu Riau dialek pesisir yang digunakan di Kecamatan Tembilahan, baik yang berupa inovasi primer maupun inovasi sekunder. Adapun inovasi primer, memiliki tiga jenis inovasi, yaitu substitusi, split, dan merger, sedangkan inovasi sekunder, terdiri atas lenisi, fortisi, metatesis, sinkope, protesis, dan paragog.
\end{abstract}

Kata kunci: diakronis, dialek Pesisir, Melayu Riau, Tembilahan

\begin{abstract}
Malay is one of languages that has many speakers. One area of Malay language speakers is Riau. Riau Malay language has few differences in the lexicons, so that it can be said as a sub-dialect. Therefore, it is important to study further about the communication language of Riau Malay, especially Riau Malay coastal dialect used in Tembilahan Subdistrict by using diachronic study. This study aims to describe the reflexes of Malay proto-language phonemes of Riau Malay coastal dialect in Tembilahan Sub-district which is then followed by making the rules of changing Malay protolanguage phonemes of Riau Malay coastal dialect in Tembilahan Sub-district and the rules for retention forms of its phonemes. The method used in this study is a qualitative deductive method that applies top-down reconstruction technique. The results obtained in this study are that Riau Malay coastal dialect used in Tembilahan Sub-district has some innovation rules, both in the forms of primary innovations and secondary innovations. The primary innovations have three types of innovations, namely substitution, split, and merger, while secondary innovations, consisting of lenition, fortition, metathesis, syncope, prothesis, and paragoge.
\end{abstract}

Keywords: diachronic, coastal dialect, Riau Malay, Tembilahan

How to Cite: Ubaidillah dan Norlaili. (2020). Inovasi dan Retensi Fonologis Proto Bahasa Melayu pada Bahasa Melayu Riau Dialek Pesisir. Ranah: Jurnal Kajian Bahasa, 9(1), 141-159. doi: https://doi.org/10.26499/rnh/v9i1.1392 


\section{PENDAHULUAN}

Bahasa Melayu adalah anggota terpenting dari kerabat bahasa Austronesia yang memiliki batasan luas, yang diluncurkan dari peradaban Asia Timur pada 1000 tahun yang lalu (Collins, 2005: 1). Bahasa Melayu merupakan salah satu bahasa dunia yang memiliki banyak pendukung. Bahasa ini diperkirakan digunakan oleh lebih dari 200 juta penutur menurut Ahmad \& Zain dalam Tuan (2004: 1).

Secara geografis, bahasa Melayu Riau dapat dibagi atas tiga dialek, yaitu (1) dialek kepulauan, (2) dialek daratan, dan (3) dialek pesisir (Dahlan et al., 1991: 1). Menurutnya, bahasa Melayu Riau dialek pesisir meliputi daerah (1) Bagan Siapi-api, (2) Dumai, (3) Sungai Pakning, (4) Bengkalis, (5) Tembilahan, (6) Selat Panjang, (7) Tanjung Batu, (8) Tanjungbalai Karimun, dan (9) Tanjungpinang.

Dalam tulisan ini dideskripsikan bahasa komunikasi dari salah satu daerah tempat bahasa Melayu Riau dialek Pesisir tersebar, tepatnya bahasa Melayu Riau dialek pesisir yang digunakan di Kecamatan Tembilahan (selanjutnya disingkat BMRT), dengan menggunakan kajian diakronis. Pembatasan ini dilakukan karena hampir pada masing-masing tempat persebaran bahasa Melayu Riau dialek Pesisir memiliki beberapa perbedaan dalam leksikonnya, sehingga bisa dikatakan sebagai subdialek. Sebagai contoh, kata "telinga" dalam bahasa Indonesia, pada daerah Tembilahan diucapkan dengan [təlijə], dan pada daerah Bagan Siapi-api diucapkan dengan [tolinO].

Adapun tujuan artikel ini adalah untuk mengetahui tentang gambaran refleks fonem-fonem protobahasa Melayu (selanjutnya disingkat BPM) pada BMRT yang kemudian dilanjutkan dengan membuat kaidah-kaidah perubahan fonem BPM pada BMRT berikut kaidah retensi fonemfonemnya. Kontribusi dari kajian ini dapat menambah pemahaman kita tentang salah satu dialek bahasa Melayu Riau dialek pesisir, yakni daerah Tembilahan yang memiliki beberapa perbedaan dengan bahasa Melayu Riau dialek-dialek pesisir lainnya ditinjau dari perspektif diakronis.

Penelitian protobahasa Melayu dengan menggunakan kajian linguistik diakronis pun telah dilakukan oleh beberapa peneliti, diantaranya penelitian yang dilakukan oleh Toha (2016) yang meneliti tentang "Retensi dan Inovasi Fonologis Protobahasa Melayik pada Bahasa Melayu Tamiang”. Di samping itu, penelitian dialektologi secara diakronis pada dialek-dialek Melayu Riau juga telah dilakukan oleh Tuan (2004) dengan memfokuskan pada kekerabatan bahasa Sakai dan bahasa Minangkabau. Dari beberapa kajian lingusitik diakronis terhadap dialek-dialek bahasa Melayu Riau tersebut, belum ditemukan kajian linguistik diakronis yang dipusatkan pada BMRT. Sebelumnya, Dahlan et al. (1991) telah melakukan penelitian terhadap struktur bahasa Melayu 
Riau dialek pesisir, tetapi menggunakan kajian linguistik sinkronis. Selain itu, Lubis et al. (1993) juga pernah melakukan penelitian secara sinkronis terhadap tata bahasa Melayu Riau. Dengan demikian, penelitian ini merupakan hal baru bagi literatur bahasa Melayu dialek Pesisir.

\section{LANDASAN TEORI}

Teori yang digunakan dalam tulisan ini ialah linguistik diakronis. Linguistik diakronis mengkaji bahasa dari perspektif waktu. Istilah diakronis dalam kajian linguistik berkenaan dengan pendekatan terhadap bahasa dengan melihat perkembangannya sepanjang waktu (Kridalaksana, 2001: 42; Anthony, 1993: 3). Objek utama linguistik diakronis adalah tentang kajian sejarah perubahan suatu bahasa, misal dari bahasa Inggris Kuno ke bahasa Inggris Modern, atau dari bahasa Semit ke bahasa Arab (Campbell, 1998: 4). Mempelajari linguistik diakronis bertujuan mengetahui sejarah perubahan suatu bahasa, komparasi bahasa, bahasa sekerabat, dan untuk mengetahui protobahasa (Campbell, 1998: 4; Fernandez, 1993: 32--33).

Untuk mengetahui kekerabatan suatu bahasa, teknik leksikostatistik yang melihat prosentase kesamaan dan perbedaan suatu bahasa dengan bahasa lain bisa dilakukan (Keraf, 1996: 121). Selain dengan teknik leksikostatistik, untuk mengetahui hubungan kekerabatan suatu bahasa dapat pula dilakukan dengan cara melihat rekonstruksi unsur retensi atau pemertahanan dan inovasi atau perubahan dari protobahasa atau bahasa asalnya (Santoso, 2015: 186). Hal ini senada dengan pernyataan Keraf (1996: 36) bahwa bahasa-bahasa yang mempunyai hubungan yang sama atau berasal dari satu protobahasa, kemudian berkembang menjadi bahasa-bahasa baru, termasuk dalam satu keluarga bahasa (language family) yang tentunya memiliki kekerabatan erat. Protobahasa merupakan suatu gagasan teoretis yang dihubungkan dengan sistem bahasa sekerabat dengan memanfaatkan kaidah-kaidah (Bynon, 1979: 71). Perubahan yang terjadi dalam suatu bahasa dengan bahasa sekerabatnya dapat diketahui dengan cara mengembalikan bahasa tersebut ke protobahasanya. Oleh karena itu, tahap paling awal yang harus dilakukan adalah mengamati inovasi bunyi pada tataran fonologisnya.

Kaidah-kaidah inovasi yang terjadi pada suatu bahasa dapat dibedakan menjadi dua jenis, yaitu inovasi primer dan inovasi sekunder.

Inovasi primer adalah perubahan-perubahan bunyi yang bersifat teratur atau korespondensi (Santoso, 2015: 186). Perubahan-perubahan bunyi yang korespondensi, yaitu substitusi, split, merger, dan pelesapan (Anttilla, 1989: 68--70). Substitusi merupakan perubahan sebuah protofonem menjadi fonem lain pada bahasa sekarang. Dengan demikian bisa dikatakan jika dalam proses substitusi terjadi sebuah pergeseran dalam protofonem menjadi fonem lain. 
Misalnya, protofonem BPM */r/menjadi $/ \gamma /$ dalam BMRT pada kata *jarum >jaqum. Istilah Split atau perengkahan ialah proses perubahan protofonem menjadi dua atau lebih fonem baru yang berbeda pada bahasa sekarang. Split merupakan proses di mana fonem tunggal asli memunculkan dua atau lebih fonem sebagai keturunannya (Trask, 1996: 268; Keraf, 1996: 83). Dalam BMRT protofonem /*u/ menjadi /U/ jika pada ultima tertutup di akhir silabel, seperti *porut >payUt. Akan tetapi, /*u/ tetap menjadi /u/ pada ultima tertutup yang diakhiri dengan fonem /N/labial, seperti *inum >minum. Apabila dua fonem atau lebih dari protobahasa mengalami perubahan menjadi satu fonem baru pada bahasa sekarang, inovasi tersebut dinamakan dengan merger atau peleburan (Keraf, 1996: 82). Jadi, merger menghilangkan dua atau lebih fonem dari bahasa asalnya. Disamping itu, merger terbagi menjadi dua tipe, yaitu merger bersyarat dan merger tidak bersyarat. Merger bersyarat adalah merger yang hanya berlaku dalam konteks terbatas. Sementara itu, merger tidak bersyarat adalah merger yang berlaku di semua konteks (Trask, 1996: 220). Dalam BMRT, protofonem /*r/ menjadi /Ø/ pada posisi ultima tertutup di akhir silabel, seperti *akar >aka.

Inovasi sekunder adalah perubahan-perubahan bunyi yang bersifat tidak teratur atau sporadis (Santoso, 2015: 186). Tipe-tipe perubahan bunyi sporadis ialah lenisi dan fortisi, lowering, metatesis, sinkope, protesis, paragog, pemecahan vokal, asimilasi, dan disimilasi (Crowley, 1992: 39--56). Lenisi yaitu perubahan bunyi fonem konsonan dari yang lebih kuat menjadi bunyi yang lebih lemah dan fortisi adalah kebalikan dari lenisi, yaitu perubahan bunyi fonem konsonan yang lebih lemah (p, f, h, w,ə, I, l, s, ?) menjadi bunyi fonem konsonan yang lebih kuat (b, p, x, v, a, i, d, s) (Crowley, 1992: 39).

\section{METODE PENELITIAN}

Menurut Sudaryanto dalam Mahsun (1995: 93) sebuah penlitian harus melalui 3 tahapan, yaitu (a) penyediaan data, (b) analisis data, dan (c) penyajian hasil.

Dalam hal penyediaan data, data primer penelitian ini bersumber dari BPM yang telah dihimpun oleh Adelaar (1985) dan BMRT yang dikumpulkan oleh Dahlan et al. (1991). Untuk memperkuat data primer ini, peneliti memberikan daftar pertanyaan berupa kosakata dasar Swadesh yang ditujukan kepada 4 orang informan, yaitu penutur asli BMRT yang tinggal di Asrama Mahasiswa Inhil (Indragiri Hilir) di Yogyakarta sehingga otentisitas fonem mereka masih terjaga karena intensitas pergaulan sehari-hari mereka di asrama bersama penutur yang berbahasa tutur sama. Selain itu, salah satu peneliti juga merupakan penutur asli BMRT sehingga pengujian keabsahan data bisa dipertanggungjawabkan. 
Dalam hal analisis data, metode yang digunakan dalam penelitian ini adalah metode penentuan dialek yang inovatif dan konservatif (Mahsun, 1995: 142) dengan menerapkan teknik rekonstruksi dari atas ke bawah (top-down reconstruction). Metode ini dilakukan dengan cara melihat unsur retensi dan inovasi dari peringkat yang lebih tinggi ke peringkat yang lebih rendah. Prosedur analisis yang ditempuh adalah melalui penemuan refleks fonem-fonem protobahasa Melayu kemudian membandingkannya dengan BMRT. Melalui kajian ini dapat dijelaskan berbagai kaidah perubahan fonologis primer maupun sekunder yang memaknai inovasi yang terjadi pada bahasa yang diteliti yang diharapkan dapat menjelaskan secara tersirat maupun tersurat sejarah perkembangan BMRT dalam kajian ini.

Dalam hal penyajian hasil, peneliti menggunakan metode informal dan formal. Metode informal dilakukan dengan cara menguraikan temuan melalui kata-kata. Sementara itu, metode formal dilakukan dengan menggunakan tanda-tanda atau lambang-lambang, seperti asterisk (*) untuk menandakan bahasa proto; (>) untuk menandakan korespondensi fonem dan sebagainya (Mahsun, 1995: 148).

\section{PEMBAHASAN}

\section{Gambaran Singkat Wilayah Pemakaian BMRT}

Kecamatan Tembilahan merupakan sebuah kecamatan yang terletak di Kabupaten Indragiri Hilir, Provinsi Riau. Kecamatan Tembilahan terletak di daerah pesisir yang memiliki luas wilayah 297,62 km², terdiri dari 6 desa. Adapun Jumlah penduduk Kecamatan Tembilahan tahun 2002 adalah 52.773 jiwa.

Kecamatan Tembilahan memiliki batas-batas wilayah sebagai berikut:

1. Sebelah utara berbatasan dengan Kecamatan Batang Tuaka.

2. Sebelah timur berbatasan dengan Kec. Kuala Indragiri dan Tanah Merah.

3. Sebelah selatan berbatasan dengan Kecamatan Enok.

4. Sebelah barat berbatasan dengan Kec. Tembilahan Hulu dan Batang Tuaka.

Kecamatan tembilahan memiliki enam kelurahan, yaitu (1) Tembilahan Kota, (2) Pekan Arba, (3) Tembilahan Hilir, (4) Sungai Beringin, (5) Sungai Perak, dan (6) Seberang Tembilahan.

Karena kecamatan ini merupakan daerah gambut, daerah ini digolongkan daerah beriklim tropis basah, apabila diperhatikan jumlah hari hujan daerah ini yang memiliki ketinggian rata-rata 2,5 meter dari permukaan laut, tercatat hari hujan yang tertinggi pada bulan Maret 1999, yaitu 11 hari, sedangkan angka yang terendah pada bulan Juni 1999, yaitu 4 hari (https://id.wikipedia.org/wiki/Tembilahan,_Indragiri_Hilir). 
Ciri-ciri keadaan iklim itu semakin menjelaskan bahwa daerah Tembilahan di Riau pesisir memang merupakan ciri salah satu tanah asal bahasa Melayu karena sebagian ahli ada yang berpendapat bahwa tanah asal bahasa Melayu adalah berasal dari daerah yang beriklim tropis basah, seperti Riau. Namun, pendapat ahli tersebut kini dibantah oleh para ahli dewasa ini dan mereka lebih menguatkan bahwa daerah Kalimantan Baratlah yang merupakan tanah asal bahasa Melayu dengan evidensi-evidensi yang lebih kuat.

\section{Deskripsi Fonem BMRT}

BMRT terdiri atas 6 buah fonem vokal, yaitu $/ i /, \mid e /, / /, / a /, / o /$, dan $/ u /$. Fonem-fonem vokal tersebut menempati semua posisi pada kata. Adapun fonem konsonan dalam BMRT terdiri atas

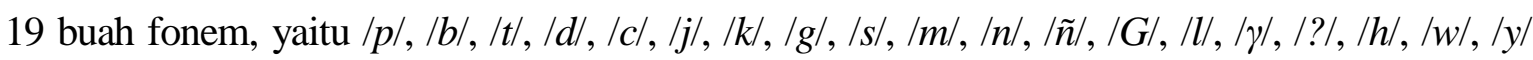
(Dahlan et al., 1991: 7--11).

Selain itu, BMRT juga memiliki 2 buah diftong, yaitu /ay/ pada kata [lantay] 'lantai', dan [sungay] 'sungai'; dan /aw/ pada kata [danaw] 'danau' dan [ijaw] 'hijau' (Dahlan et al., 1991: 24).

\section{Refleksi Proto fonem BPM pada BMRT}

Setelah mengamati dan membandingkan fonem-fonem BPM dengan BMRT, ditemukan adanya inovasi-inovasi pada BMRT, baik yang terjadi secara teratur maupun sporadis. Adapun inovasi-inovasi tersebut bisa dijelaskan dengan kaidah-kaidah sebagai berikut.

\section{Inovasi Primer}

Dari data-data yang ada, dapat dijelaskan bahwa fonem-fonem BPM yang mengalami inovasi pada BMRT secara teratur adalah sebagai berikut.

\subsection{Substitusi}

(1) $*_{r}>\gamma /$ tanpa syarat, seperti
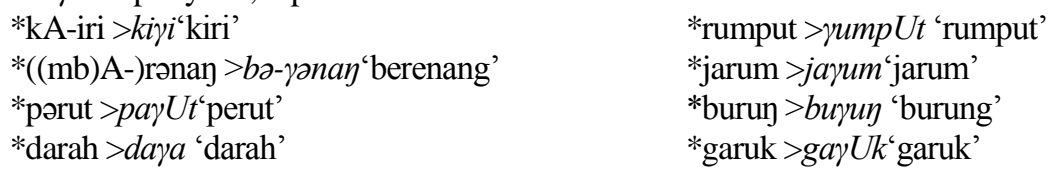

Adelaar menggunakan */r/ sebagai fonem proto dari $/ \mathrm{r} /$ dan $/ \gamma /$, karena leksikon pada dialekdialek bahasa Melayu yang dikumpulkannya, sebagian besar menggunakan fonem /r/, dan hanya sedikit yang menggunakan fonem $/ \gamma /$, khususnya pada dialek-dialek Melayu Riau.

Pada data tersebut */r/ BPM mengalami inovasi pada BMRT menjadi / $\gamma /$ dengan model substitusi dan tanpa syarat. Di mana pun posisi fonem */r/ BPM, baik pada penultima terbuka dan tertutup di awal silabel maupun ultima terbuka dan tertutup di akhir silabel, tetap mengalami inovasi menjadi fonem $/ \gamma /$ pada BMRT, seperti pada data tersebut. 
(2) $* \mathrm{~h}>\varnothing / \# \_V$ - (pada penultima terbuka di awal silabel), seperti
*hati >ati 'hati'
*hiduy >iduy'hidung'
*hidup >idUp'hidup'
*hutan > utan'hutan'
*hatəp > atap 'atap'
*habu>abu 'abu'
*hitəm >itam 'hitam'
*hujan > ujan'hujan'
*hijaw >ijaw'hijau’
kecuali pada: *hitun > hituๆ 'hitung'

Pada data di atas, fonem */h/ BPM mengalami inovasi dengan model substitusi pada BMRT menjadi fonem / $\varnothing$ / atau fonem zero pada penultima terbuka di awal silabel. Semua fonem $* / \mathrm{h} /$ BPM disubstitusi menjadi fonem / $\varnothing$ / atau tidak dituturkan pada BMRT seperti pada data tersebut, kecuali pada leksem *hitun > hitun yang tetap mengalami retensi fonologis.

(3) $* \mathrm{~h}>\varnothing /$ __VK\# (pada ultima tertutup), seperti

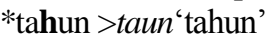

*tuha(?) >tuə'tua'

Pada data ini fonem */h/ BPM mengalami inovasi pada BMRT menjadi fonem / $\varnothing$ / atau fonem zero pada ultima tertutup diakhir silabel seperti "hun" pada kata "tahun" menjadi /un/ sehingga tidak dituturkan.

(4) *ə > a / -K_K\# (pada ultima tertutup di tengah silabel), seperti

\begin{tabular}{|c|c|c|}
\hline (5) *datəy >datay 'datang' & *asəp > asap 'asap' & *dəyər > dəクar'dengar' \\
\hline *hitəm >itam ‘hitam’ & *hatəp >atap'atap' & *tikəm > tikam'tikam' \\
\hline *bənər > bəna'benar' & *ulər > ula'ular' & *təbəl >tabal 'tebal' \\
\hline *jahət > jahat'jahat' & $*(\mathrm{~d}-)$ aləm $>$ dalam & *dəkət >dekat 'dekat' \\
\hline *bukən > bukan'bukan' & *tanəm >tanam 'tanam' & *ləmək > lamak'lemak \\
\hline
\end{tabular}

Fonem /*a/ pada BPM mengalami inovasi pada BMRT berupa substitusi menjadi fonem /a/ pada ultima tertutup seperti pada kata *datang. Pada kata ini pengucapan silabel terakhir /təy/ diucapkan menjadi /tay/.

(6) $* a>$ ə / -K_\#; -_\# (pada ultima terbuka di akhir silabel), seperti

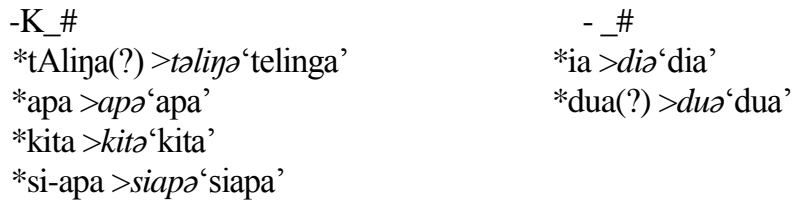

Data tersebut menunjukkan inovasi substitusi fonem /*a/ pada BPM menjadi fonem /ə/ pada BMRT. Inovasi ini terjadi pada ultima terbuka di akhir silabel seperti pada kata *apa yang mengalami perubahan pengucapan di akhir silabel dari */pa/ menjadi /po/.

Untuk fonem */?/ yang diletakkan dalam tanda kurung pada kata *tAlina(?) dan *dua(?) adalah sebuah opsi bagi kata yang memiliki proto ganda (doublet), yaitu *tAlina dan *tAlina?; *dua dan *dua?. Jadi, dalam contoh ini penulis mengambil opsi yang pertama, yang diakhiri dengan ultima terbuka, bukan opsi yang kedua yang diakhiri dengan ultima tertutup, dalam hal ini diakhiri dengan fonem */?/. 
(7) *A > ə/\#K_- (pada antipenultima terbuka di awal silabel), seperti

*bAlakay > bolakay 'belakang' *tAlina(?)>tolinə'telinga'

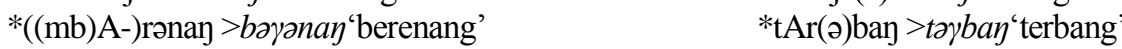

Fonem BPM $/ * \mathrm{~A} /$ pada data tersebut mengalami inovasi substitusi menjadi / $/$ / pada fonem BMRT. Inovasi ini terjadi pada antipenultima terbuka di awal silabel seperti pada kata *bAlakay. Pada kata ini pengucapan silabel /*bA/ mengalami inovasi menjadi /bə/. Kecuali pada kata

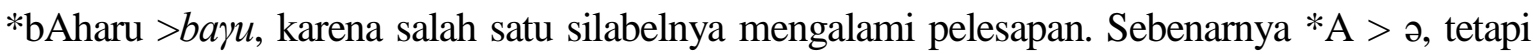
karena fonem /h/ dilesapkan maka fonem /ə/ dan /a/ yang berdekatan mengalami sandi menjadi

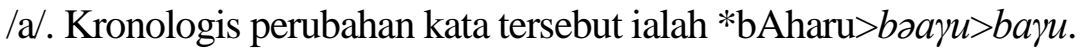

\subsection{Split}

Kaidah primer yang berupa split ini dapat ditemukan pada dua kaidah berikut.

(8) $* \mathrm{u}>\mathrm{U} /$-K_K\# (pada ultima tertutup), seperti

\begin{tabular}{|c|c|}
\hline *porut >pa Ut 'perut' & *takut >takUt'takut' \\
\hline *duduk >dudUk 'duduk' & *pukul >pukUl 'pukul' \\
\hline *garuk >ga $U k^{6}$ garuk' & *tumpul >tumpUl'tumpul' \\
\hline *tumbuk > tumbUk 'tumbuk' & *jatuh > jatUh'jatuh’ \\
\hline *tikus >tikUs 'tikus' & *busuk > busUk'busuk' \\
\hline
\end{tabular}

Pada data tersebut, inovasi yang terjadi adalah perubahan pengucapan pada fonem BPM /*u/ menjadi /U/ pada fonem BMRT. Contohnya seperti pada kata *porut. Pada kata ini terjadi inovasi pengucapan pada ultima tertutup di akhir silabel seperti pengucapan /rut/ menjadi $/ \gamma U t$, kecuali pada ultima tertutup yang diakhiri dengan fonem /N/ labial dan /N/ velar, atau pada ultima tertutup yang diawali dengan fonem $/ \mathrm{u} / \mathrm{itu}$ sendiri, fonem $/ \mathrm{u} /$ tidak mengalami inovasi, seperti

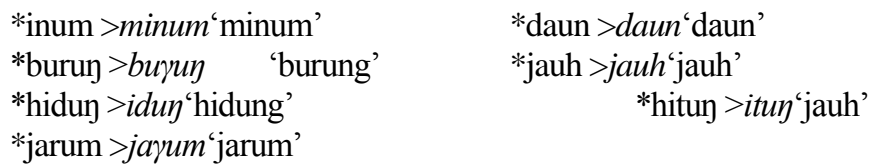

Pada data tersebut, pengucapan fonem /u/ pada BPM mengalami retensi atau pemertahanan bunyi pada fonem BMRT. Retensi pada data di atas terjadi pada penultima terbuka seperti pengucapan $/ * \mathrm{bu} /$ menjadi /bu/ di awal silabel maupun ultima tertutup seperti pengucapan /ruy/ menjadi / $z u \eta /$ di akhir silabel pada kata *buruy di BPM.

(9) $* u>o /-K \_K \#$ (pada ultima tertutup yang diakhiri dengan fonem $/ r /$ ), seperti

*tidur $>$ tido'tidur'

*telur >telo'telur'

Kedua data tersebut mengalami inovasi berupa split pada fonem vokal BPM /*u/ menjadi /o/ pada fonem vokal BMRT. Inovasi ini terjadi pada ultima tertutup di akhir silabel yang di akhiri dengan fonem konsonan $/ r /$. Contohnya adalah pada kata *tidur di BPM. Silabel terakhir pada kata 
ini mengalami perubahan pengucapan dari /dur/ menjadi /do/ di BMRT. Kaidah primer yang bersifat split ini dapat digambarkan sebagai berikut.

$* \mathrm{u}$

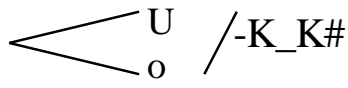

\subsection{Merger}

Kaidah primer yang berupa merger ini dapat ditemukan pada dua kaidah berikut.

(10) ${ }^{r} \mathrm{r}>\varnothing /-K V \_\#$ (pada ultima tertutup), seperti

\begin{tabular}{|c|c|c|}
\hline *tidur > tido'tidur' & *pasir >pasa'pasir' & *telur >telo'telur' \\
\hline *akar >aka'akar' & *bəsar > bəsa 'besar' & *bənər > bəna'benar' \\
\hline $\begin{array}{l}\text { *libar >leba'lebar' } \\
\text { *air >ag'air' }\end{array}$ & *bakar > baka'bakar' & *ulər > ula 'ular' \\
\hline
\end{tabular}

Pada data tersebut, inovasi yang terjadi adalah perubahan pengucapan pada fonem konsonan BPM /*r/ menjadi fonem /Ø/ pada BMRT. Perubahan ini terjadi pada ultima tertutup di akhir silabel seperti pada kata *air di BPM yang mengalami inovasi pengucapan dari /ir/ menjadi /ə/ di BMRT sehingga bisa dikatakan bahwa fonem /r/ pada kata *air tidak diucapkan atau Ø.

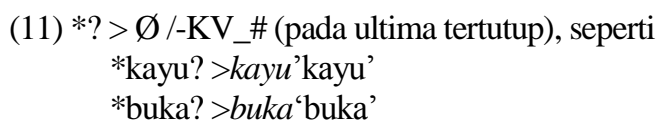

Data pada kata *kayu? dan *buka pada BPM mengalami inovasi berupa perubahan pengucapan dari fonem /?/ menjadi /Ø/ pada BMRT. Inovasi ini terjadi pada ultima tertutup di akhir silabel seperti pengucapan silabel /yu?/ dan /ka?/ pada BPM menjadi / $/ \mathrm{u} / \mathrm{dan} / \mathrm{ka} / \mathrm{pada}$ BMRT sehingga kaidah primer yang bersifat merger ini dapat digambarkan sebagai berikut.

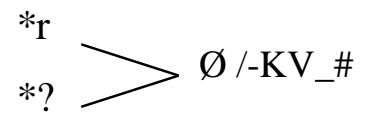

\section{Inovasi Sekunder}

Selain inovasi primer, fonem-fonem BPM pada BMRT juga mengalami inovasi yang bersifat sporadis atau sekunder berupa perubahan bunyi. Adapun perubahan bunyi yang ditemukan adalah berupa lenisi, fortisi, lowering, metatesis, sinkope, protesis, dan paragog. Hal ini bisa dilihat pada data berikut.

\subsection{Lenisi dan Fortisi}

(12) Lenisi

*b $>$ w pada *babah $>$ bawah'bawah'

*k $>$ ? pada *biluk $>$ bElo? 'belok' 
Inovasi sekunder yang terjadi pada data di atas adalah terjadi lenisi atau perubahan bunyi fonem konsonan yang lebih kuat seperti /*b/ dan /*k/ pada BPM menjadi bunyi yang lebih lemah $/ w /$ dan /?/ pada fonem konsonan BMRT. Inovasi ini terjadi pada ultima tertutup di akhir silabel yaitu perubahan pengucapan silabel /bah/ dan /luk/ menjadi /wah/dan /lo?/ pada kata *babah dan *biluk.

(13) Fortisi

$\begin{array}{lll}*_{1}>? & \text { pada } & * \text { kacil }>\text { keci? 'kecil' } \\ *_{\mathrm{n}}>t & \text { pada } & * \text { nipis }>\text { tipis }\end{array}$

Pada data tersebut fonem konsonan yang lebih lemah seperti /*1/ dan /*n/ pada BPM mengalami perubahan bunyi menjadi fonem konsonan yang lebih kuat /?/ dan /t/ pada BMRT. Inovasi ini terjadi pada ultima tertutup di akhir silabel seperti pada kata *kecil di BPM yang mengalami perubahan bunyi dari /cil/mejadi /ci?/ di BMRT. Inovasi fortisi pada data di atas juga terjadi pada penultima terbuka seperti pada kata *nipis di BPM yang mengalami perubahan bunyi pada awal silabel /ni/ menjadi /ti/ pada pengucapan di BMRT.

\subsection{Lowering}

Data (14) di bawah ini menunjukkan adanya proses lowering berupa perendahan bunyi fonem vocal tinggi $/ * \mathrm{i} /, / * \mathrm{u} /$, dan $/ *$ a/ pada BPM menjadi fonem vocal yang rendah $/ e /, / o /$, dan $/ E /$ pada BMRT. Inovasi sekunder ini terjadi pada penultima tertutup seperti pada kata *timbak di BPM yang mengalami perubahan bunyi dari /tim/ menjadi /tem/ pada awal silabel dan penultima terbuka seperti pada kata *uray yang mengalami perubahan bunyi di awal silabel dari /u/ menjadi /o/. Inovasi ini juga terjadi pada ultima tertutup di akhir silabel seperti pada kata *putih di BPM yang mengalami perubahan bunyi fonem vocal tinggi dari/tih/menjadi/teh/ di BMRT.

(14) $\quad *_{\mathrm{i}}>$ e pada*putih >puteh'putih'; *libar >leba 'lebar'

*ikur >eko'ekor'; *timbak >tembak 'tembak'

*u $>o$ pada*uray >oyay'orang'

*a $>E$ pada*pandak $>p E n d E k^{\prime}$ pendek'

\subsection{Metatesis}

Kata * dilah pada BPM mengalami inovasi sekunder berupa metatesis yang mengakibatkan adanya perubahan bunyi pada BMRT karena dua fonem bertukar tempat, yaitu fonem konsonan /d/ pada penultima terbuka di awal silabel dan /l/ pada ultima tertutup di akhir 
silabel bertukar tempat menjadi fonem konsonan /l/ yang berada pada penultima terbuka di awal silabel dan fonem konsonan / $d /$ yang berada pada ultima tertutup di akhir silabel.

(15) *dilah >lidah'lidah'

\subsection{Sinkope}

Inovasi sekunder pada data (16) mengalami proses perubahan bunyi berupa sinkope. Inovasi ini terjadi pada penultima terbuka di awal dan di tengah silabel dan antipenultima terbuka di awal silabel. Contohnya pada kata *bAharu di BPM mengalami perubahan bunyi menjadi

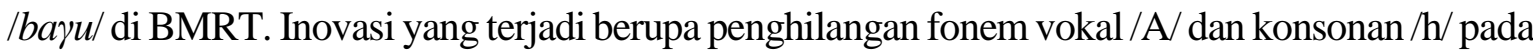
tengah kata.

(16) *kA-iri >kiji'kiri'; *(ma-)irah >meyah'merah'; *bAharu >baru'baru'

\subsection{Protesis}

Pada data (17) inovasi sekunder yang terjadi adalah protesis berupa perubahan bunyi karena penambahan fonem di kosakata BPM pada penultima terbuka dan tertutup di awal silabel di kosakata BMRT. Contohnya adalah pada kata *apa(?) di BPM yang mengalami perubahan bunyi berupa penambahan fonem konsonan $/ b /$ pada penultima terbuka di awal silabel sehingga bunyi kata *apa(?) di BPM berubah menjadi /bapa?/ di BMRT.

(17) *apa(?) >bapa? 'bapak'; *buni >sembuñi? 'sembunyi'; *ia >dia'dia'

\subsection{Paragog}

Kata *buni pada BPM data (18) mengalami perubahan bunyi yang terjadi berupa penambahan fonem /?/ pada akhir kata sehingga kata *buni berubah menjadi /sambuñi?/ pada BMRT. Inovasi ini terjadi pada ultima di akhir silabel. Dengan penambahan fonem /?/, ultima terbuka pada BPM berubah menjadi ultima tertutup pada BMRT.

(18) *buni >sambuñi?‘sembunyi’

\section{Retensi}

Masih banyak ditemukan fonem-fonem BPM yang tidak mengalami inovasi dalam BMRT. Fonem-fonem itu masih terlihat bertahan seperti yang terdapat dalam protobahasanya, baik fonem-fonem vokal maupun fonem-fonem konsonan. Retensi fonem-fonem BPM pada BMRT itu dapat dilihat pada contoh-contoh berikut.

\subsection{Retensi Vokal}

(19) *a >a / \#K_-; \#_- (pada penultima terbuka di akhir silabel) dan -_K\# (pada ultima tertutup di tengah silabel), seperti 


\begin{tabular}{|c|c|c|}
\hline \# $\mathbf{K}_{-}-$ & \#_- & $-\_\mathbf{K} \#$ \\
\hline *tanan >tayan 'tangan' & *apa(?) > bāpa?'bapak’ & *dilah > lidah 'lidah \\
\hline *k/anan > kanan'kanan' & *akar >aka'akar' & *ludah >ludah'ludah' \\
\hline *kaki > kaki'kaki’ & *apa >арә 'ара' & *uap > puap'uap' \\
\hline *jalan > jalan'jalan’ & *air >aə'air' & *kuñah > kuñah'kunyah’ \\
\hline *datəy > datay'datang' & *alir > a us 'alir' & *uran >oyay 'orang' \\
\hline *tahu(?) >tahu'tahu' & *a(bw)an > awan 'awan' & *(ə)ma(?) >ma? 'ibu' \\
\hline *takut>takUt'takut' & *api >api`api’ & *rumah > rumah'rumah' \\
\hline$>d a \gamma a h^{\prime} \mathrm{d}$ & *asəp > asap'asap' & h > bolah'belah' \\
\hline rambut > yambut 'rambut' & *atas > atas'atas' & 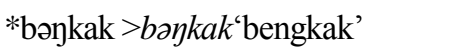 \\
\hline
\end{tabular}

Retensi vokal yang terjadi pada data tersebut ialah bunyi fonem */a/ pada BPM yang mengalami pemertahanan di BMRT. Retensi fonem */a/ terjadi baik pada penultima terbuka dan ultima tertutup. Salah satu contohnya ialah kata */bintang/ pada BPM yang mengalami retensi pada BMRT. Retensi ini terjadi pada ultima tertutup pada akhir silabel /tang/ di BPM yang mengalami retensi di BMRT menjadi /tay/.

(20) $*_{i}>i$ / \#K_- (pada penultima terbuka di akhir silabel); -K_\# (pada ultima terbuka diakhir silabel) dan -K_K\# (pada ultima tertutup di tengah silabel), seperti

\begin{tabular}{|c|c|c|}
\hline -K_K\# & \#K_- & -K_\# \\
\hline *tanis $>n$-ayis 'menangis' & *hidū >iduy 'hidung' & *api >api 'api', \\
\hline *baik > baik'baik’' & *kita > kitə'kita' & *hari >avi'hari' \\
\hline *kəcil > kaci? 'kecil' & *ia >dia'dia' & *hati >ati'hati' \\
\hline *sakit >sakit'sakit' & *gigit > gigit' 'gigit' & *tali > tali'tali' \\
\hline *kulit > kulit'kulit' & *tidur > tido'tidur' & *kaki > kaki 'kaki' \\
\hline *naik >naik'naik' & *(i)tu(?) >itu'itu' & *laki >laki 'lelaki' \\
\hline *səmpit >səmpit'sempit' & *hituy >itUy'hitung' & $* \mathrm{di}>d i^{6} \mathrm{di}$ \\
\hline *jahit $>\tilde{n}$-jahit 'menjahit' & 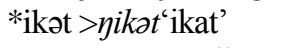 & *buni >sambuñi? \\
\hline$*^{m} /$ ati $>$ mati ${ }^{6}$ mati & *tikəm > tikam'tikam' & *gigi > gigi‘'gigi’ \\
\hline
\end{tabular}

Pada data tersebut fonem vokal /*i/ di BPM mengalami retensi sehingga memiliki bunyi fonem vokal /i/ yang sama di BMRT. Retensi vokal tersebut terjadi pada penultima terbuka dan ultima terbuka dan tertutup. Contoh retensi yang terjadi pada ultima terbuka adalah bunyi vokal /i/ pada kata */hati/ di BPM yang diucapkan /ati/ di BMRT sehingga bunyi vokal /i/ pada silabel di akhir memiliki bunyi yang sama yaitu */ti/ pada BPM dan /ti/ pada BMRT.

(21) $* u>\mathrm{u}$ / \#K_- (pada penultima terbuka di akhir silabel); -K_\# (pada ultima terbuka di akhir silabel) dan K_K-\# (pada ultima tertutup di tengah silabel), seperti

\#K_-

*kulit > kulit'kulit'

*tulay >tulay'tulang'

*m/u(n)tah >muntah'muntah'

*ludah >ludah 'ludah'

*kuñah >kuñah 'kunyah'

*uap > -uap'uap'

*bunuh > bunUh'bunuh'
K_K-\#

*mulut >mul $U t$ ' 'mulut'

*inum >minum 'minum'

*jarum > jarum 'jarum'

*daun > daun 'daun'

*tahun $>$ taun 'tahun'

*jauh > jauh 'jauh'

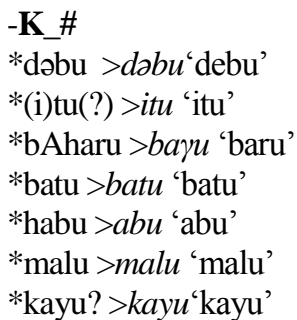

*kayu? > kayu'kayu'

Fonem vokal /u/ di BPM pada data tersebut mengalami retensi sehingga bunyi vokalnya tetap berbunyi /u/ di BMRT. Retensi fonem vokal /u/ terjadi pada penultima terbuka dan ultima terbuka dan tertutup. Contoh retensi fonem vokal pada penultima terbuka ialah pada kata *bunuh 
di BPM yang diucapkan /bunUh/ di BMRT. Silabel di awal kata tersebut berbunyi /bu/ pada BPM dan /bu/ pada BMRT.

\subsection{Retensi Konsonan}

(22) $* \mathrm{~b}>b /$ pada semua posisi, seperti

*babah > bawah 'bawah' *bAharu >baru'baru'

*bakar >baka 'bakar' *bAlakan > bəlakaG 'belakang'

*batu > batu 'batu' *bolah > balah 'belah'

*baik > baik'baik' *borat $>$ bryat 'berat'

*biluk > belo? 'belok' *bini > bini ' 'istri'

Pada data tersebut fonem konsonan /b/ pada BPM tidak memiliki perubahan sehingga memiliki bunyi yang sama pada BMRT menjadi /b/. Retensi fonem konsonan /b/ terjadi pada penultima terbuka di awal silabel seperti pada kata *batu di BPM yang diucapkan /batu/ di BMRT. Retensi fonem konsonan /b/ juga terjadi pada penultima tertutup di awal silabel dan ultima tertutup dan terbuka di akhir silabel sehingga bisa dikatakan bahwa fonem konsonan /b/ mengalami retensi pada semua silabel.

(23) *d >d/\#_V-(pada penultima terbuka di awal silabel) dan -_VK\# (pada ultima tertutup di awal silabel), seperti \#_V-

*-_agin $>$ dagin $\quad$ 'daging' $\quad$ *'ludah $>$ ludah 'ludah'

*dahan > dahan 'dahan' *tidur >tido 'tidur'

*darah $>$ dajah 'darah' *hidup >idUp 'hidup'

*datəy $>$ datay $\quad$ 'datang' *pandak $>p E n d E k$ 'pendek'

Data tersebut menunjukkan adanya retensi pada fonem konsonan /d/ pada BPM yang mengalami pemertahanan bunyi pada fonem konsonan /d/ pada BMRT. Retensi fonem konsonan /d/ terjadi pada penultima terbuka dan ultima tertutup. Contohnya ialah pada kata *darah di BPM yang diucapkan /dayah/ di BMRT. Retensi fonem konsonan /d/ terjadi pada penultima terbuka di awal silabel /da/ di BPM yang berbunyi sama pada silabel di awal/da/ di BMRT.

(24) *g > g /\#_V- (pada penultima terbuka di awal silabel) dan -_VK\# (pada ultima tertutup di awal silabel), seperti

\#_V-

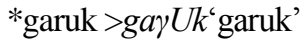

*gigi > gigi'gigi'

*gigit > gigit' gigit'

\section{- VK\#}

*dagin > dagin 'daging'

*pogay >pagay 'pegang'

Retensi yang terjadi pada data tersebut adalah pemertahanan fonem konsonan/g/ pada BPM sehingga berbunyi sama pada fonem konsonan /g/ pada BMRT. Retensi fonem konsonan /g/ terjadi pada penultima terbuka di awal silabel, seperti pada kata *garuk, *gigi, dan *gigit pada BPM yang diucapkan sama pada BMRT, seperti /ga UK/, /gigi/, dan /gigit/. Retensi fonem konsonan /g/ juga terjadi pada ultima tertutup di akhir silabel pada kata *dagij sehingga diucapkan /gin/ di BPM dan /gin/ di BMRT. 
(25) $* \mathrm{~h}>h /-\mathrm{KV} \_\#$; -_VK\# (pada ultima tertutup di awal dan akhir silabel), seperti

\begin{tabular}{|c|c|}
\hline -KV_\# & \\
\hline *babah >bawah & 'bawah' \\
\hline *buah >buah & ‘buah’ \\
\hline *tanah >tanah & 'tanah' \\
\hline *kuñah > kuñah & 'kunyah' \\
\hline
\end{tabular}

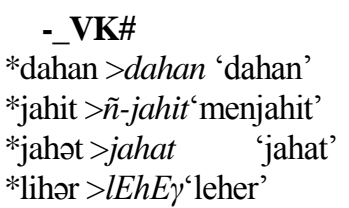

Fonem konsonan /h/ di BPM pada data tersebut tidak mengalami inovasi melaikan retensi di BMRT sehingga fonemnya tetap berbunyi / $h /$. Retensi fonem konsonan /h/ terjadi pada ultima tertutup. Contohnya ialah pada kata *tanah di BPM yang diucapkan/tanah/ di BMRT. Pada kata ini, silabel yang berada di akhir diucapkan /nah/ di BPM dan /nah/ di BMRT sehingga bisa dikatakan bahwa bunyi keduanya sama pada pengucapan bunyi fonem konsonan $/ \mathrm{h} /$.

(26) $*_{j}>j$ /\#_V- (pada penultima terbuka) dan_VK\# (pada ultima tertutup), seperti

\begin{tabular}{|c|c|c|}
\hline \#_V- & & _VK\# \\
\hline *jahət $>$ jahat & 'jahat' & *hijaw >ijaw'hijau' \\
\hline$*$ jahit $>\tilde{n}$-jahit & 'menjahit' & *hujan > ujan 'hujan’ \\
\hline *jalan $>$ jalan & 'jalan’ & *pañjan >panjay 'panjang' \\
\hline *jarum > jarum & ‘jarum’ & *tajəm >tajam 'tajam' \\
\hline *jatuh $>$ jatUh & ‘jatuh’ & \\
\hline *jauh > jauh & ‘jauh’ & \\
\hline
\end{tabular}

Pada data tersebut fonem konsonan /j/ di BPM mengalami retensi bunyi pada fonem konsonan /j/ di BMRT. Retensi fonem konsonan /j/ terjadi pada penultima terbuka, seperti pada kata *jauh di BPM yang diucapkan /jauh/ di BMRT sehingga bisa dikatakan silabel di awal pada kata tersebut diucapkan sama, yaitu/ja/ di BPM dan/ja/ di BMRT. Retensi juga terjadi pada ultima tertutup seperti pada kata *hujan di BPM yang diucapkan /ujan/ di BMRT. Sehingga bisa dikatakan silabel di akhir pada kata tersebut diucapkan sama yaitu /jan/ di BPM dan /jan/ di BMRT.

(27) $* \mathrm{k}>\mathrm{k} / \# \_\mathrm{V}$ - (pada penultima terbuka) dan_VK\# ; KV_\# (pada penultima tertutup), seperti

\begin{tabular}{|c|c|c|c|c|}
\hline \#_V- & & _VK-\# & & V_\# \\
\hline *k/anan > kanan & 'kanan' & $*$ tikus $>$ tikUs & ‘tikus’' & *ləmək >ləmak 'lemak' \\
\hline$*$ kabut $>k a b U t$ & 'kabut' & *buka? > buka & ‘buka’' & *m/asak >masak'masak' \\
\hline$*_{\mathrm{kA}}$-iri $>$ kiyi & 'kiri' & *bukən > bukan & 'bukan' & *anak >anak 'anak' \\
\hline *kaki > kaki & 'kaki' & *tikəm > tikam & ‘tikam’ & *baik > baik 'baik' \\
\hline$* \operatorname{kau}(?)>k a u$ & 'kau’' & *dəkət >dəkat & 'dekat' & *duduk >dudUk 'duduk' \\
\hline *kayu? > kayu & 'kayu’' & *pukul >pukUl & 'pukul' & 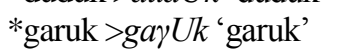 \\
\hline *kuñah > kuñah & 'kunyah' & *akar >aka & 'akar' & *naik > naik 'naik' \\
\hline
\end{tabular}

Fonem konsonan */k/ pada BPM tersebut mengalami retensi pada BMRT sehingga memiliki bunyi yang sama yaitu $/ k /$. Retensi fonem konsonan $/ \mathrm{k} /$ terjadi pada penultima terbuka dan tertutup. Contohnya ialah pada kata */akar/ di BPM yang diucapkan /aka/ di BMRT. Retensi 
fonem konsonan /k/ pada kata tersebut terjadi pada ultima tertutup di akhir silabel /kar/ di BPM dan $/ k a /$ di BMRT.

(28) $* 1>l /$ pada semua posisi, seperti:

$\begin{array}{lll}\text { *tulay > tulay 'tulang' } & \text { *pilih > pilih 'pilih' } & \text { *malu > malu 'malu' } \\ \text { *laki >laki 'lelaki' } & \text { *lantay >lantay 'lantai' } & \text { *bulu > bulu 'bulu' } \\ \text { *lihər >lEhEy 'leher' } & \text { *bolah > bolah 'belah' } & \text { *libar >leba'lebar' } \\ \text { *tali > tali 'tali' } & \text { *biluk > belo? 'belok' } & \text { *ulər > ula 'ular' }\end{array}$

Data di atas menunjukkan adanya retensi pada fonem konsonan $/ 1 /$, sehingga bisa dikatakan bahwa fonem konsonan /// di BPM berbunyi sama dengan fonem konsonan /l/ di BMRT. Retensi bunyi tersebut terjadi pada semua sisi, baik pada penultima terbuka dan tertutup dan ultima terbuka dan tertutup. Contohnya ialah pada kata *lantay di BPM yang diucapkan /lantay/ di BMRT. Pada kata ini retensi fonem konsonan /1/ terjadi pada penultima terbuka, yaitu pada silabel di awal /lan/ di BPM dan /lan/ di BMRT.

(29) *m >m / \#_V-dan \#KV_- (pada penultima terbuka di awal silabel dan tertutup diakhir silabel); -_VK\# dan $\mathrm{KV}$ \# (pada ultima tertutup dengan posisi di awal dan akhir silabel), seperti

$$
\text { \#_V- }
$$

*m/asak >masak 'masak

*m/ati >mati 'mati'

*mulut >mulUt 'mulut'

*mata >mato 'mata'

*ma/kan >makan 'makan'

*malu >malu 'malu'

$$
\begin{aligned}
& \text {-_VK\# } \\
& \text { *ləmək > ləmak 'lemak' } \\
& \text { *ñamuk > ñamok 'nyamuk' } \\
& \text { *rumah > yumah 'rumah' } \\
& \text { *(ə)ma(?) >ma? 'ibu' }
\end{aligned}
$$

\#KV_-

*rambut > rambUt 'rambut'

*ompat >ampat 'empat'

*rumput > rumpUt 'rumput'

*səmpit >sampit 'sempit'

*t/um/buh >tumbUh 'tumbuh'

*timbak >tembak 'tembak'

$$
\begin{aligned}
& \text {-KV_\# } \\
& \text { *hitəm > itam 'hitam' } \\
& \text { *inum > minum 'minum' } \\
& \text { *jarum > jarum 'jarum' } \\
& \text { *tanəm > tanam 'tanam' } \\
& \text { *tajəm > tajam 'tajam' } \\
& \text { *tikəm > tikam 'tikam' }
\end{aligned}
$$

Retensi yang terjadi pada data tersebut ialah pemertahanan bunyi fonem konsonan $/ \mathrm{m} /$ pada BPM yang memiliki bunyi yang sama pada fonem konsonan $/ \mathrm{m} /$ pada BMRT. Retensi pada fonem konsonan $/ \mathrm{m} /$ terjadi pada penultima tertutup dan terbuka dan ultima tertutup. Contohnya ialah seperti pada kata *ñamuk di BPM yang diucapkan /ñamok/ di BMRT. Retensi fonem konsonan $/ \mathrm{m} /$ pada kata tersebut terjadi pada ultima tertutup, yaitu pada silabel di akhir yang berbunyi /muk/ di BPM dan /mok/ di BMRT sehingga bisa dikatakan bahwa baik bunyi fonem konsonan /m/ di BPM dan BMRT tidak mengalami inovasi bunyi.

(30) $*_{n}>n$ / pada semua posisi, seperti

*naik > naik'naik'

*bintay > bintay 'bintang'

*ma/kan >makan 'makan'

*lantay >lantay'lantai'

*tahun >taun *panah > panah 'panah'

*panas >panas 'panas'

*anak >anak 'anak'

*bənər > bəna 'benar'

*hutan > utan 
/s/ pada kata tersebut terjadi pada penultima terbuka, yaitu pada silabel di awal kata yang berbunyi /pa/ di BPM dan berbunyi /pa/ di BMRT.

(33) $*_{t}>t /$ pada semua posisi, seperti

\begin{tabular}{|c|c|c|}
\hline ttiup >tiUp ‘tiup' & *bintay > bintay 'bintang' & *səmpit >sampit 'sempit' \\
\hline *talu & *atas >atas 'atas' & *rumput > $>u m p U t$ 'rumput' \\
\hline *tahu(?) >tau 'tahu' & *hatəp > atap 'atap' & *rambut > rambUt rambut' \\
\hline "tahun >taun 'tahun' & *hitəm > itam 'hitam' & *mulut >mulUt ‘mulut' \\
\hline jəm >tajam 'tajam' & *hitun >itug 'hitung' & 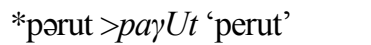 \\
\hline "takut >takUt 'takut' & *datəy > datay 'datang' & *ikət > $>$-ikət 'mengikat' \\
\hline *tali >tali 'tali' & *jatuh > jatUh ‘jauh’ & *əmpat >əmpat 'empat' \\
\hline
\end{tabular}

Data tersebut menunjukkan adanya retensi pada fonem konsonan /t/ di BPM yang berbunyi sama pada fonem konsonan /t/ di BMRT. Retensi fonem konsonan /t/ terjadi pada semua posisi, baik pada penultima terbuka dan tertutup maupun ultima terbuka dan tertutup. Contohnya ialah pada kata *t/um/buh di BPM yang diucapkan /tumbUh/ di BMRT. Retensi fonem konsonan /t/ pada kata tersebut terjadi pada penultima tertutup, yaitu pada silabel di awal kata yang berbunyi /t/um/ di BPM dan/tum/ di BMRT. Antara bunyi fonem konsonan /t/ di BPM dan fonem konsonan /t/ di BMRT tidak berubah sehingga dikatakan bahwa fonem konsonan /t/ pada keduanya mengalami retensi.

\section{PENUTUP}

BMRT adalah sebuah subdialek dari bahasa Melayu Riau dialek pesisir karena setiap daerah persebaran bahasa Melayu Riau dialek pesisir hampir semuanya memiliki perbedaan fonem pada leksikonnya meskipun masih dalam lingkup satu dialek. Misalnya, kata telinga pada dialek pesisir Tembilahan diucapkan dengan [təlinə] dan pada dialek pesisir Bagan Siapi-api diucapkan dengan [təlinO].

Setelah melakukan rekonstruksi pada perangkat kognat BPM terhadap BMRT, ternyata refleks fonem-fonem BPM pada BMRT banyak yang mengalami retensi, dengan rincian sebagai berikut. 1) *a >a / \#K_-; \#_-; 2) *i >i / \#K_-, -K_\#, -K_K\#; 3) *u > u / \#K_-, -K_\#, K_K-\#; 4) *b $>b$ pada semua posisi; 5) *d >d/ \#_V-, -_VK\#; 6) *g > g / \#_V-, -_VK\#, 7) *h >h / -KV_\# ; _VK\#; 8) *j >j /\#_V-, _VK\#; 9) *k >k/ \#_V-, _VK\#, KV_\#; 10)*1 >l pada semua posisi, 11) *m $>m$ / \#_V-, \#KV_-; -_VK\#, -KV_\#, 12)*n >n pada semua posisi,13)*p > p pada semua posisi, dan 14) *s >s / \#_V-, \#_VK-, -_VK\#, -KV_\#

Adapun inovasi fonologis yang dialami BPM pada BMRT dapat dijelaskan dengan beberapa kaidah inovasi, baik yang berupa inovasi primer maupun inovasi sekunder. Adapun inovasi primer memiliki tiga jenis inovasi, yaitu substitusi yang terjadi pada: 1) ${ }^{*}>\gamma /$ tanpa syarat, 
2) *h > Ø /\#_V-, -_VK\#; 3) *ə> a / -K_K\#; 4) *a > ə / -K_\# , -_\#; 5) *A > ə /\#K_-; split yang terjadi pada 1$) * \mathrm{u}>\mathrm{U} /-\mathrm{K} \_\mathrm{K} \#$; 2) ${ }^{*} \mathrm{u}>\mathrm{o} / \mathrm{-K} \_\mathrm{K} \#$; dan merger yang terjadi pada 1 ) ${ }_{\mathrm{r}}>\varnothing /$ -

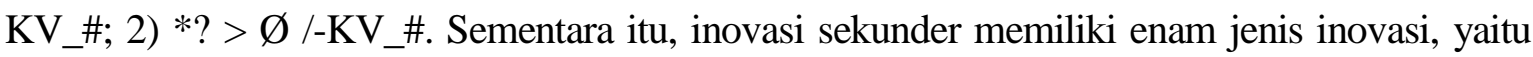
lenisi yang terjadi pada ${ }^{\mathrm{b}}>\mathrm{w}$, *k $>$ ?; fortisi yang terjadi pada $* \mathrm{l}>$ ?, ${ }_{\mathrm{n}}>t$; metatesis hanya pada kata *dilah >lidah; sinkope seperti kata *kA-iri >kiji; *(ma-)irah >merah; *bAharu >baru; protesis seperti pada kata *apa(?) >bapa?; *buni >sembuñi?; *ia >diz; dan paragog seperti pada kata *buni >səmbuñi?

Meskipun secara fonologis terdapat beberapa inovasi, tetapi secara leksikal, lebih dari $81 \%$ mengalami retensi pada kosakata dasar. Hal ini membuktikan bahwa BMRT memang termasuk anggota bahasa Melayu yang tentunya jarak usia keberpisahan dengan bahasa protonya tidak begitu jauh. Menurut teori yang diajukan Keraf(1996: 125) dari persentase retensi yang mencapai lebih dari $81 \%$ ini, jarak usia keberpisahan dengan bahasa protonya adalah dalam kurun waktu 500 tahun. Menurut Handayani (2016: 128) terjadinya retensi juga dapat dipengaruhi dari sikap positif pengguna bahasa, berupa kebanggaan dan kesetiaan terhadap bahasa yang mereka miliki.

\section{DAFTAR PUSTAKA}

Adelaar, K. A. (1985). Proto-Malayic: the reconstruction of its phonology and parts of its lexicon and morphology. Albasserdam: Kanters.

Anonim. (2019). Tembilahan, Indragiri Hilir. Diakses 15 Maret 2019. https://id.wikipedia.org/wiki/Tembilahan,_Indragiri_Hilir

Anthony, A. (1993). Introduction to Historical Linguistics. USA: University Press of USA.

Anttila, R. (1989). An Introduction to Historical Linguistics. New York: The Mac Milian Company.

Bynon,T. (1979). Historical Linguistics. Cambridge: Cambridge University Press.

Campbell, L. (1998). Historical Linguistik an Introduction. Edinburgh: Edinburgh University Press.

Collins, J. T. (2005). Bahasa Melayu Bahasa Dunia: Sejarah Singkat. Terjemahan Malay, World Language: a Short History oleh Alma Evita Almanar. Jakarta: Yayasan Obor Indonesia.

Crowley, T. (1992). An Introduction to Historical Linguistics. New York: Oxford University Press.

Dahlan, S., Ramli, B., Razak, A., Zainal, A., \& Bahri, S. (1991). Struktur Bahasa Melayu Riau Dialek Pesisir. Jakarta: Departemen Pendidikan dan Kebudayaan.

Fernandez, I. Y. (1993). Dialektologi Sinkronis dan Diakronis Sebuah Pengantar. Handout. Yogyakarta.

Handayani, R. (2016). "Kebanggaan Masyarakat Sebatik terhadap Bahasa Indonesia, Bahasa Daerah, dan Bahasa Asing: Deskripsi Sikap Bahasa di Wilayah Perbatasan".Ranah: Jurnal Kajian Bahasa. Vol.5 no.2. Halaman 125-138. https://doi.org/10.1017/CBO9781107415324.004

Keraf, G. (1996). Linguistik Bandingan Historis. Jakarta: PT Gramedia Pustaka Utama.

Kridalaksana, H. (2001). Kamus Linguistik. Jakarta: PT Gramedia Pustaka Utama. 
Lubis, M., Zainal, A., \& Bahri, S. (1993). Tata Bahasa Melayu Riau. Jakarta: Departemen Pendidikan dan Kebudayaan.

Mahsun, (1995). Dialektologi Diakronis: Sebuah Pengantar. Yogyakarta: Gadjah Mada University Press.

Santoso, T. (2015). "Refleks Fonem Proto Austronesia pada Bahasa Aceh". Diksi.Volume 12, Nomer 2, Halaman 185-203. https://doi.org/10.21831/diksi.v12i2.5264

Toha, M. (2016). "Retensi dan Inovasi Fonologis Protobahasa Melayik Pada Bahasa Melayu Tamiang". Ranah: Jurnal Kajian Bahasa. Vol. 5(1). https://doi.org/10.26499/rnh.v5i1.40

Trask, R. L., (1996). A Dictionary of Phonetics and Phonology. New York: Routledge. https://doi.org/10.4324/9780203695111

Tuan, N. T. (2004). "Dialek-dialek (Isolek) Melayu Riau: Sebuah Model Kajian Dialektologi Bahasa Melayu". Makalah Program Studi Linguistik Pascasarjana UGM. Yogyakarta: Universitas Gadjah Mada. 